\title{
ASPECTOS GERENCIAIS DE BIBLIOTECÁRIOS COM FOCO NA LIDERANÇA EM UNIDADES DE INFORMAÇÃO
}

\section{MANAGERIAL ASPECTS OF LIBRARIES WITH A FOCUS ON LEADERSHIP IN INFORMATION UNITS}

\author{
Marília Cossich Ramos \\ Mestre em Biblioteconomia \\ Bibliotecária do Instituto de Matemática da UFRJ \\ Biblioteca da Pós-Graduação em Matemátca \\ mariliacossich@gmail.com
}

Resumo

\begin{abstract}
Apresenta os atributos e competências necessários ao bibliotecário-gestor no exercício de liderança em Unidades de informação. Aponta as funções gerenciais da Administração aplicadas ao exercício biblioteconômico. Destaca a capacidade de liderança como um atributo desejável ao trabalho de gestão do bibliotecário. Tem por objetivo identificar os atributos e as competências gerenciais necessárias ao exercício profissional do bibliotecário-gestor que atua em Unidades de informação. A metodologia empregada foi uma revisão de literatura, sendo caracterizada por uma pesquisa descritiva com abordagem qualitativa. Os resultados foram as reflexões acerca do perfil gerencial do bibliotecário como gestor de Unidades de informação. Conclui ressaltando a importância das habilidades gerenciais no perfil do bibliotecário para a liderança na gestão de Unidades de informação.
\end{abstract}

Palavras-chave: Competências profissionais. Gestão de bibliotecas. Unidades de informação.

\begin{abstract}
It presents the attributes and skills needed by the librarian-manager in the exercise of leadership in Information Units. It points out the management functions of the Administration applied to the library exercise. It highlights leadership skills as a desirable attribute to the librarian's management work. It aims to identify the attributes and managerial skills necessary for the professional practice of the librarian-manager who works in Information Units. The methodology used was a literature review, characterized by a descriptive research with a qualitative approach. The results were reflections on the managerial profile of the librarian as manager of Information Units. It concludes by emphasizing the importance of managerial skills in the profile of the librarian for leadership in the management of Information Units.
\end{abstract}

Keywords: Professional skills. Library management. Information units.

\section{INTRODUÇÃO}

O bibliotecário nos últimos anos tem se transformado num profissional cada vez mais dinâmico, com um perfil bastante diversificado e com habilidades e competências que lhes são cada vez mais exigidas. A biblioteca exerce um papel importante na preservação da identidade cultural de uma nação, sendo o lugar onde se armazenam o patrimônio intelectual e o conhecimento científico, constituindo um centro institucional com a função de promover o acesso à informação e a disseminação do conhecimento.

De acordo com Maciel e Mendonça (2000a, p.7) “[...] biblioteca é uma organização de valor social relevante, com fins lucrativos não necessariamente financeiros, com uma estrutura 
capaz de atingir os resultados esperados e avaliados sistematicamente". O termo organização refere-se ao complexo sistema de comunicações e inter-relações existentes num grupamento humano. Este sistema proporciona a cada membro do grupo parte substancial das informações, objetivos e atitudes que fazem parte de suas decisões, também chamado por sistema de papéis (SIMON, 1979). Já os conceitos de missão e propósito de uma organização são imprescindíveis para um melhor entendimento do papel da organização na sociedade. Com as bibliotecas é o mesmo caso, sendo assim:

Com o intuito de melhor atender à sociedade, as bibliotecas foram segmentadas dando origem à variadas tipologias tais como, bibliotecas escolares, públicas, universitárias, especializadas, infantis entre outras, cada uma com uma missão e um público alvo diferenciado o que, consequentemente, enfatiza a necessidade de uma administração que busca atender aos objetivos institucionais propostos (BARBALHO; SILVA; FREITAS, [20-?], p.10).

A missão de uma organização pode ser entendida como a sua razão de ser, portanto é ela quem irá nortear suas ações para o alcance de seus propósitos. O "negócio" das Unidades de informação é disseminar informações precisas e prestar assistência a empresas, para que iniciem (tomada de decisão), mantenham e concluam (execução da ação) as necessárias mudanças tecnológicas, comerciais e gerenciais que assegurarão sua evolução e sobrevivência.

Neste sentido o processo de gestão nas organizações, sejam públicas ou privadas, vem sofrendo mudanças em função da necessidade de adequação às exigências da sociedade da informação onde o capital humano é valorizado a partir de sua capacidade de explorar suas habilidades e competências. As organizações contemporâneas estão cada vez mais preocupadas com as questões ligadas ao comportamento de seus gestores, que tem influência direta nas tomadas de decisão e no gerenciamento da organização. À medida que as organizações se desenvolvem e se tornam mais complexas, faz-se necessário uma preocupação maior com a sua administração.

Para atuar num cenário onde a incerteza é uma constante, as organizações em geral e as bibliotecas em particular, com suas peculiaridades, precisam se adequar à situação atual, principalmente aquelas organizações com propostas apresentadas sob uma rigidez estrutural, que não as permitam mais atender aos propósitos para os quais foram criadas (MACIEL; MENDONÇA, 2000b). Historicamente estas instituições enfrentaram dificuldades financeiras e políticas, e isto permanece até hoje pelo fato de serem órgãos ligados, na maioria das vezes, a um organismo federal, estadual ou municipal, o que evidencia uma dependência não só financeira, mas ideológica que compromete as ações administrativas (BARBALHO; SILVA; FREITAS, [20?]).

Segundo Dias (1985b) a preocupação com a administração de bibliotecas só começou a acontecer recentemente e recomenda: há uma grande necessidade de se dar mais atenção à administração de bibliotecas como um meio de enfrentar os problemas, sempre presentes de escassez de recursos e também para aumentar a eficácia nesse aspecto do trabalho do bibliotecário. No entanto faz-se necessário conhecer as funções de um gerente, para que se possa repensar as funções do gerente-bibliotecário como forma de introduzir melhorias em seu desempenho.

Dentre os diversos problemas enfrentados pelas bibliotecas brasileiras podemos destacar: a escassez de usuários, a obsolescência de seus acervos, a carência de material tecnológico, falta de atualização profissional, políticas públicas inadequadas, formação profissional não coerente com a realidade social e o distanciamento da população que, na maioria das vezes, desconhece os produtos e serviços oferecidos pelas bibliotecas. Estes são alguns dos grandes desafios para aqueles que gerenciam e atuam em Unidades de informação.

Com o avanço tecnológico e o acesso fácil à internet os estudantes têm procurado cada vez menos as bibliotecas, visto que as mesmas encontram-se a cada dia mais vazias. Sendo assim, diante dos problemas de gestão é preciso que o gestor de Unidades de informação tenha percepção e sensibilidade para identificar os fatores prejudiciais ao desempenho da biblioteca e atrair o interesse da comunidade de usuários. Para tal, é necessário que o profissional possua 
determinados atributos e competências a fim de se alcançar o melhor resultado para a organização e para a equipe de trabalho.

Este estudo tem por objetivo identificar os atributos e as competências gerenciais necessárias ao exercício profissional do bibliotecário-gestor que atua em Unidades de informação. Numa abordagem da biblioteca como uma organização, as teorias administrativas da Administração moderna são importantes de serem correlacionadas com o desempenho esperado de uma biblioteca.

No presente artigo as funções gerenciais (planejamento, organização, direção e controle) são explicitadas a fim de se descrever as atribuições de um bibliotecário-gestor, segundo as teorias administrativas numa Unidade de informação. Na sequência são expostas as habilidades gerenciais, de acordo com os níveis organizacionais de uma instituição. A fim de se estabelecer características importantes no comportamento gerencial, habilidades e competências do bibliotecário no exercício de sua função, a liderança é identificada como um aspecto fundamental no perfil deste profissional.

Através de uma revisão de literatura procurou-se observar as características relevantes ao comportamento organizacional e as competências gerenciais dos bibliotecários responsáveis por uma Unidade de informação.

\section{A ADMINISTRAÇÃO E O BIBLIOTECÁRIO}

No século XX, Frederick W. Taylor e Henri Fayol desenvolveram os primeiros trabalhos sobre Administração. Taylor fundou a chamada Escola de Administração Científica, cuja abordagem baseava-se nas partes (operários) para o todo (organização empresarial). Já Fayol desenvolveu a Teoria Clássica, cuja abordagem se dava do todo para as partes, onde predominava a ênfase na estrutura organizacional (ANDRADE; AMBONI, 2006). Ambas as teorias constituem o alicerce da abordagem clássica da Administração, evidenciando o que hoje chamamos de Administração das Organizações. Porém, tais teorias refletiam apenas os interesses da produção sem se preocupar com a questão humana. Em oposição à Teoria Clássica, surge em 1920 a Teoria das Relações Humanas, refletindo as necessidades das pessoas. A partir daí o papel do gerente passa a ser ampliado e direcionado para o alcance dos objetivos da organização. Ainda nesse contexto de mudanças surge a Teoria comportamental da Administração trazendo novas abordagens sobre o comportamento humano nas organizações, não evidenciando mais a estrutura mas a preocupação com o comportamento das pessoas na organização (ANDRADE; AMBONI, 2006).

Muitas são as definições atribuídas a Administração, por diversos autores, porém um traço comum que frequentemente aparece em cada uma delas é a preocupação em atingir metas ou objetivos organizacionais. Para Hersey e Blanchard (1986, p.4) a administração pode ser definida "[...] como trabalhar com e por meio de pessoas e grupos para alcançar objetivos organizacionais". Nesta definição os autores não mencionam nenhum tipo de organização em específico, pois a mesma se aplica a qualquer organização, seja ela empresarial, educacional, política, até mesmo as sem fins lucrativos. Para serem bem-sucedidas, tais organizações necessitam que seus gestores saibam lidar com pessoas, consequentemente que alcancem os objetivos organizacionais por meio da liderança.

Segundo Newman (1976, p.15) "[...] a administração consiste em orientar, dirigir e controlar os esforços de um grupo de indivíduos para um objetivo comum". O bom administrador é aquele que possibilita ao grupo alcançar seus objetivos com o mínimo de dispêndio de recursos e de esforço.

Enquanto administrador o bibliotecário permanentemente utilizará a tomada de decisões no que se refere a estabelecer objetivos e organizar os recursos para atingir metas. É preciso que o bibliotecário conheça as principais técnicas administrativas, como nos diz:

[...] as técnicas administrativas são em grande número, e hoje fazem parte de um campo de conhecimento ensinado em escolas de administração para formar profissionais do ramo. No entanto, dirigentes devem obter informações sobre algumas técnicas fundamentais, não para praticá-las, mas para familiarizarem- 
se com suas dimensões básicas e saber utilizar com mais eficiência os especialistas da área (MOTTA, 1998, p.39).

A utilização das técnicas administrativas começou a despertar a atenção dos bibliotecários em meados da década de 1950 nos Estados Unidos. Atualmente o bibliotecário além de aplicar seus conhecimentos tradicionais inerentes à profissão, também pode atuar como administrador de bibliotecas, exercendo a função de gestor, na qual estão inseridas as funções de planejar, organizar, comandar, coordenar e controlar todas as atividades ligadas a Unidade de informação. Para tal função será necessário dispor de conhecimentos técnicos e administrativos que lhe permitam manter as diretrizes, traçar metas, estabelecer planos e políticas (MACIEL; MENDONÇA, 2000a).

É importante aos gerentes (bibliotecários) conhecerem as tendências administrativas contemporâneas, assim como as teorias administrativas que as fundamentam, para que possam ser adaptadas e aplicadas às bibliotecas, pois embora sejam organizações sem fins lucrativos, as mudanças ambientais fazem-nas assumir algumas características semelhantes às das organizações privadas.

Para Motta (1998, p.26) “[...] a gerência é a arte de pensar, de decidir e de agir; é a arte de fazer acontecer, de obter resultados. Resultados que podem ser definidos, [...] mas que têm de ser alcançados através das pessoas e numa interação humana constante". Conforme Drucker (1986, p.13) "[...] qualquer trabalhador com conhecimentos, nas organizações modernas, é um gerente se, [...] for responsável por uma contribuição que afeta, materialmente, a capacidade da organização de trabalhar e de obter resultados".

O bibliotecário-administrador atuará em situações de incerteza, instabilidade e imprevisibilidade que são desafios propostos pela competitividade do mundo moderno. Atualmente em Administração a ênfase é dada à teoria das organizações e para o profissional que possui a capacidade de compreender a organização como um todo, bem como seus objetivos e o papel social que desempenha dentro de tal estrutura (KATZ, 1986 apud ANDRADE; AMBONI, 2006).

Tem sido cada vez mais exigido dos profissionais da informação o perfil de administrador, sendo necessário lidar com situações no qual o trabalho em equipe e a cooperação são fundamentais para o alcance dos objetivos organizacionais. $\mathrm{O}$ desempenho de uma organização pode ser mensurado à medida que seus objetivos são atingidos, dentro de um determinado contexto. Quando a organização consegue alcançar seus objetivos, previamente estabelecidos, dizemos que agiu com eficácia. Já quando a organização utiliza a racionalidade econômica, ou seja, a razão custo/benefício e ainda assim, consegue atingir seus objetivos, dizemos que agiu com eficiência.

\section{FUNÇÕES GERENCIAIS EM UNIDADES DE INFORMAÇÃO}

As funções gerenciais numa biblioteca são aquelas de ordem administrativa, responsáveis pelo direcionamento e ajuste das metas e objetivos da organização. Segundo Motta (1998, p.20) "[...] já se aceita tratar a função gerencial como extremamente ambígua e repleta de dualidades, cujo exercício se faz de forma fragmentada e intermitente. Com isso, torna-se difícil defini-la de forma análoga a outras profissões".

As mudanças têm acontecido cada vez mais rapidamente no cenário mundial, nacional e organizacional devido ao desenvolvimento da ciência e tecnologia, afetando assim as organizações no tocante às estruturas e às formas de gerência (MACIEL; MENDONÇA, 2000b).

De acordo com Dias (1985b) “[...] os estudiosos que, por tradição, procuram descrever o conteúdo do trabalho gerencial fizeram-no em termos das funções clássicas da Administração [...] ou por meio de atividades como passar informações ou tomar decisões".

Sendo assim as funções básicas de um administrador aplicadas ao serviço de gestão de Unidades de informação são as seguintes:

- Planejar: significa estabelecer metas e objetivos para a organização e o desenvolvimento de planos de trabalho; planejar em Unidades de informação implica em caracterizar o ambiente no qual se 
pretende implantar um serviço. Para isso é necessária uma análise do contexto no qual a biblioteca está inserida que justifique sua existência e/ou a qualidade dos serviços e produtos;

- Organizar: compreende a alocação de recursos humanos, financeiros e técnicos, de modo a otimizar a consecução das metas; a organização é a função que se propõe a estabelecer a estrutura organizacional necessária para o desempenho das atividades e consequentemente ao alcance dos objetivos da empresa; em Unidades de informação é preciso definir claramente a missão e os propósitos da instituição a fim de se traçar os planos para atingir seus objetivos;

- Dirigir: envolve os estilos de direção empregados pelos gestores para atingir os objetivos e alcançar a missão; a função de direção compreende ações relacionadas ao preenchimento de cargos, comunicação, liderança e motivação de pessoal, assim como a direção para o alcance dos objetivos organizacionais;

- Controlar: estabelece uma relação entre os objetivos esperados e os resultados alcançados; o controle verifica se os resultados planejados estão sendo alcançados por meio das ações executadas, visando a corrigir possíveis desvios durante o processo também conhecido como avaliação. Numa Unidade de informação o gestor busca avaliar o desempenho de determinado serviço ou função visando à detecção de erros e a aplicação das devidas correções.

O administrador é uma pessoa fundamental para qualquer tipo de organização, seja governamental, comercial ou de prestação de serviços. Para que as funções do administrador funcionem na prática, a retroação, também conhecida por feedback, possibilita ao gestor efetuar ajustes de acordo com as normas estabelecidas pela organização (ANDRADE; AMBONI, 2006). Quanto as características do trabalho gerencial, Dias (1993a) afirma que:

As características do trabalho gerencial dizem respeito a elementos mais objetivos, tais como o lugar em que o gerente trabalha, o tempo que despende com o serviço, a quantidade de trabalho e os meios de comunicação utilizados. Essas características são elementos importantes no estudo da função gerencial, na medida em que implicam habilidades específicas que podem ser requeridas dos gerentes.

De acordo com Hersey e Blanchard (1986) as habilidades gerenciais são consideradas as seguintes:

- Técnica: é a capacidade de aplicar conhecimentos, técnicas e métodos necessários à execução de tarefas específicas e é adquirida através da experiência, da educação e do treinamento;

- Humana: é a capacidade e o discernimento para trabalhar com e por meio de pessoas, incluindo o conhecimento do processo de motivação e a aplicação eficaz da liderança;

- Conceitual: é a capacidade de compreender a complexidade da organização como um todo e onde cada área específica se enquadra nesse complexo; permite agir de acordo com os objetivos globais da organização e não em função de metas e necessidades imediatas do próprio grupo.

Estas habilidades inerentes ou trabalhadas em um profissional situam-se de acordo com o nível organizacional da instituição (operacional, tático ou estratégico) como podemos visualizar no Quadro 1. 
Quadro 1: Relação entre os níveis organizacionais e as habilidades gerenciais

\begin{tabular}{|c|c|}
\hline Nível organizacional & Habilidade gerencial \\
\hline Estratégico & Conceitual \\
\hline Tático & Humana \\
\hline Operacional & Técnica \\
\hline
\end{tabular}

Elaborado pela autora segundo Hersey e Blanchard.

São estas habilidades que em conjunto com atitudes desejáveis ao profissional bibliotecário (criatividade, cooperação, participação, atuação interdisciplinar, capacidade de análise, sensibilidade para o valor da informação como vantagem competitiva, senso crítico, comprometimento com os objetivos organizacionais, ousadia e liderança) é que permitirão ao gestor ter uma atuação em consonância com os objetivos da organização. Cada profissional deve administrar a instituição onde atua de acordo com a tipologia que a caracteriza, pois é isso que irá definir sua função dentro do contexto social e político.

Com a introdução de novas tecnologias e a consequente mudança na postura do profissional bibliotecário, a biblioteca deixa de ser uma simples catalisadora de informações e o bibliotecário, um mero guardador livros. Sendo assim o bibliotecário assume uma nova condição de administrador e líder, adotando uma postura ágil e dinâmica com uma visão moderna de gestão e organização. Para Motta (1998, p.22) “[...] a função do dirigente é essencialmente voltada para a decisão. Mas a compreensão do trabalho do dirigente jamais pode ser feita exclusivamente pelo estudo da decisão em si". É necessário que os gerentes observem as novas perspectivas exigidas às empresas, cujos pontos fundamentais se apoiam na visão estratégica, na preocupação com a qualidade, na produção com a criatividade e na satisfação dos clientes/usuários. Além disso, pensa-se sobre o gerente:

Normalmente, pensa-se num gerente como um indivíduo numa organização, provido de poder legítimo (autoridade) para dirigir as atividades relacionadas ao trabalho de, no mínimo, um subordinado. Sendo assim, neste contexto, um gerente é um líder. Todavia, há mais na gerência do que a simples liderança [...] (KOONTZ; O’DONNELL, 1990).

A atividade de gestão se dedica ao sucesso do empreendimento, e para tal, o gerente deve assumir em seu comportamento as seguintes características:

- Estrategista;

- Inovador;

- Empreendedor;

- Competitivo.

Alguns fatores contextuais estão influenciando o comportamento gerencial dos profissionais, tais como: o desenvolvimento de novas tecnologias e o crescimento do uso e valorização da informação. Com isso é necessário que os gestores observem as novas perspectivas exigidas pelo mercado, onde a visão estratégica, a preocupação com a qualidade dos serviços prestados e a satisfação dos usuários são peças fundamentais para o sucesso da organização.

É evidente que produzir e implementar são papéis importantes, porém em um ambiente em constante mutação o gerente deve ter discernimento, critério para mudar as metas e os métodos utilizados para atingi-las. 


\section{A LIDERANÇA EM UNIDADES DE INFORMAÇÃO}

Diante da importância dada à liderança e a gestão nas organizações, e consequentemente as competências indispensáveis para a realização do trabalho de gestão, incluindo a liderança, o trabalho do bibliotecário-gestor vem sendo fundamental para o sucesso da organização.

A questão da liderança no contexto de uma Unidade de informação traz à tona a importância do posto de comando no ambiente organizacional, no qual o gerente é a mola propulsora responsável pela sobrevivência e sucesso, ou não, de uma organização. Uma razão por que existem tantas teorias sobre liderança é que diferentes pesquisadores direcionam o foco para elementos diferentes. Como nos diz:

Por um lado, todas estas teorias estão certas, pois identificam a liderança como um componente central da complexa situação humana, mas por outro, pecam pela falta de preocupação com o fato de que as organizações possuem necessidades e problemas distintos em diferentes estágios de sua evolução (SCHEIN, 1996, p. 82).

É comum pensar que administração e liderança são a mesma coisa, já que frequentemente há este tipo de pensamento, porém há uma diferença importante entre os dois conceitos. Liderança é um conceito mais amplo que Administração, que é um tipo especial de liderança, em que é de fundamental importância à consecução dos objetivos organizacionais. Portanto a principal distinção entre estes dois conceitos está na palavra organização. A liderança ocorre sempre que alguém procura influenciar o comportamento de um indivíduo ou de um grupo, qualquer que seja a finalidade, sendo coerente ou não com os objetivos organizacionais (HERSEY; BLANCHARD, 1986).

Segundo Motta (1998, p.207) “[...] líderes são pessoas comuns que aprendem habilidades comuns, mas que no seu conjunto formam uma pessoa incomum". Para que se atinja o êxito na gestão de uma Unidade de informação é necessário o trabalho em equipe e o foco na satisfação dos usuários. E para um bom trabalho em equipe é preciso que haja a presença de um líder. A liderança tem um grande impacto na vida das organizações, pois sem a liderança as empresas correm o risco de perderem a direção de suas atividades.

De acordo com Motta $(1998$, p.207) " $[. .$.$] a liderança pode ser vista como uma função$ gerencial, embora evidentemente, não seja privativa da gerência. Outras pessoas de um mesmo grupo, instituição ou empresa podem exercê-la, independentemente de ocuparem posições gerenciais".

Para Bowditch e Buono (1992, p.118) "[...] a liderança pode ser considerada como um processo de influência, geralmente de uma pessoa, através do qual um indivíduo ou grupo é orientado para o estabelecimento e atingimento de metas". Chiavenato (2003, p.122) define liderança como sendo "[...] necessária em todos os tipos de organização humana, seja nas empresas, seja em cada um de seus departamentos". Para Motta (1998) a ideia de liderar é mais simpática e atraente do que a de administrar, comandar, dirigir ou gerenciar. Isto porque na função de supervisão o indivíduo necessita possuir a capacidade de influenciar os outros, sendo assim o dirigente influenciaria no comportamento dos seus liderados e em troca, receberia admiração e reconhecimento.

Segundo Belluzzo (2002) a liderança divide-se em autocrática, democrática e liberal. Sendo assim podemos afirmar que o líder deve:

- Focar nos objetivos a serem alcançados;

- Orientar-se para a ação;

- Ter confiança em si próprio e no grupo;

- Ter habilidade para lidar e conviver com pessoas;

- Ser criativo e inovador;

- Ser flexível, estar aberto a mudanças;

- Tomar decisões (pensar e agir diante de uma situação); 
- Desenvolver altos padrões de desempenho e avaliação, buscando excelência, eficiência, eficácia, produtividade e qualidade.

Dentre as qualidades individuais requeridas a um líder podemos citar: conhecimento de si próprio, iniciativa, coragem, persistência e integridade (MOTTA, 1998). O exercício de liderança também exige capacidade de comunicação e expressão, e também habilidade para trabalhar em equipe. A capacidade de liderança não é mais vista como algo inato ou de simples estilo pessoal, mas sim de competência gerencial, por isso tem-se incentivado ultimamente o aprendizado sobre liderança (MOTTA, 1998).

Hoje admite-se que a liderança pode ser aprendida a fim de se obter uma transformação de características no comportamento gerencial dos gerentes. Em uma Unidade de informação na qual o bibliotecário exerça o cargo de chefe e consequentemente gerencie uma equipe de trabalho é desejável a aplicação de todas estas recomendações dadas à situação de liderança.

Um enfoque dado à liderança é a abordagem situacional, na qual o comportamento do líder é visto tal como é observado, e não atribuído a alguma habilidade ou potencialidade inata ou adquirida. De acordo com a liderança situacional, o líder deve possuir um comportamento adaptativo, ou seja, adaptar seu estilo de comportamento conforme a situação específica e às necessidades dos seus subordinados, a fim de ser mais eficaz na consecução dos objetivos organizacionais (HERSEY; BLANCHARD, 1986). Ainda de acordo com a liderança situacional não existe um único modo de influenciar as pessoas, sendo assim o estilo de liderança adotado dependerá do nível de maturidade das pessoas que o líder pretende influenciar.

\section{PROCEDIMENTOS METODOLÓGICOS}

Trata-se de uma pesquisa bibliográfica e descritiva, de abordagem qualitativa, pois se desejou descrever as características e atributos desejáveis ao profissional bibliotecário-gestor, identificando a liderança como um traço de seu novo perfil. Segundo Gil (2002) [...] a pesquisa descritiva tem como objetivo primordial à descrição das características de determinadas populações ou fenômenos. Para tal foi realizada uma revisão da literatura utilizando fontes secundárias para consulta, tais como: livros e artigos de periódicos científicos.

\section{CONSIDERAÇÕES FINAIS}

A biblioteca é uma instituição com grande valor social e necessita de um profissional à sua frente capacitado para gerenciar e contornar os problemas relacionados à explosão informacional e ao avanço tecnológico, dentre outros de origem burocrática, econômica, social e cultural.

Levando-se em conta o que foi observado, este estudo possibilitou verificar a relevância de habilidades e competências gerenciais em bibliotecários para a gestão de Unidades de informação. Observou-se a partir da análise da literatura que as funções gerenciais como planejamento, organização, direção e controle podem ser aplicadas para a administração de Unidades de informação. Percebeu-se a contribuição da liderança para o sucesso da organização, sendo uma habilidade desejável no trabalho administrativo dos profissionais futuros.

Recomenda-se como sugestão a trabalhos futuros novos estudos abordando a liderança, embora já existam na literatura diversos trabalhos, porém sob novas perspectivas da profissão do bibliotecário e da administração.

\section{REFERÊNCIAS}

ANDRADE, Rui Otávio B.; AMBONI, Nério. Teoria Geral da Administração. São Paulo: M. Books, 2006.

BARBALHO, Célia Regina Simonetti; SILVA, Carla Maria T. de S. C.; FREITAS, Kellem Andrezza de Araújo. Gestão de bibliotecas: um estudo sobre o perfil do bibliotecário-gestor na 
cidade de Manaus. [20-?] Disponível em:

http://www.geocities.ws/biblioestudantes/texto_52.pdf. Acesso em: 28 dez. 2020.

BELLUZZO, R. C. B. Liderança e formação e desenvolvimento de equipes. São Paulo: USP, 2002.

BOWDITCH, James L.; BUONO, Anthony F. Elementos de comportamento organizacional. São Paulo: Pioneira, 1992.

CHIAVENATO, Idalberto. Introdução à teoria geral da administração. 7.ed. Rio de Janeiro: Elsevier, 2003.

DIAS, B. de F. Fatores que afetam a avaliação nas universidades federais. 1993. Dissertação (Mestrado em Administração). Universidade Federal de Santa Catarina: Florianópolis, 1993a.

DIAS, Eduardo José Winse. A abordagem dos papéis gerenciais de Mintzberg e sua aplicação a bibliotecas e centros de informação. Revista da Escola de Biblioteconomia da UFMG, Belo Horizonte, v.14, n.1, p.37-54, mar. 1985b.

DRUCKER, Peter Ferdinand. O gerente eficaz. 10.ed. Rio de Janeiro: Guanabara, 1986.

GIL, Antônio Carlos. Como elaborar projetos de pesquisa. 4.ed. São Paulo: Atlas, 2002.

HERSEY, Paul; BLANCHARD, Kenneth H. Psicologia para administradores: a teoria e as técnicas da liderança situacional. São Paulo: EPU, 1986.

KATZ, Robert L. As habilitações de um administrador eficiente. São Paulo: Nova Cultural, 1986.

KOONTZ, H; O’DONNELL. C. Princípios de Administração. São Paulo: Pioneira, 1990.

MACIEL, Alba Costa; MENDONÇA, Marília Alvarenga Rocha. Bibliotecas como organizações. Rio de Janeiro: Interciência, 2000a.

. A função gerencial na biblioteca universitária. Rio de Janeiro: UFF, 2000b.

Disponível em: https://app.uff.br/riuff/handle/1/479. Acesso em: 28 dez. 2020.

MOTTA, Paulo Roberto. Gestão contemporânea: a ciência e a arte de ser dirigente. 9.ed. Rio de Janeiro: Record, 1998.

NEWMAN, William Herman. Ação administrativa: as técnicas de organização e gerência. 4.ed. São Paulo: Atlas, 1976.

SCHEIN, Edgar H. Liderança e cultura organizacional. In: HESSELBEIN, Frances et al (Ed.). O líder do futuro. São Paulo: Futura, 1996.

SIMON, Herbert Alexander. Comportamento administrativo: estudo dos processos decisórios nas organizações administrativas. 3.ed. Rio de Janeiro: Fundação Getúlio Vargas, 1979. 